\title{
Hypoglossal Nerve Palsy Due to Internal Carotid Artery Dissection
}

The Neurohospitalist

2018, Vol. 8(4) 199

(C) The Author(s) 2017

Article reuse guidelines:

sagepub.com/journals-permissions

DOI: $|0.1| 77 / 194|8744| 77367 \mid$

journals.sagepub.com/home/ $\mathrm{NHO}$

(S)AGE

\section{William Allingham, BSc', Vinodh Devakumar, MSc, FRCP ${ }^{2}$, Amit Herwadkar, $\mathrm{FRCR}^{3}$, and Martin Punter, PhD, FRCP ${ }^{1,3}$}

\section{Keywords}

stroke, headache, internal carotid artery dissection

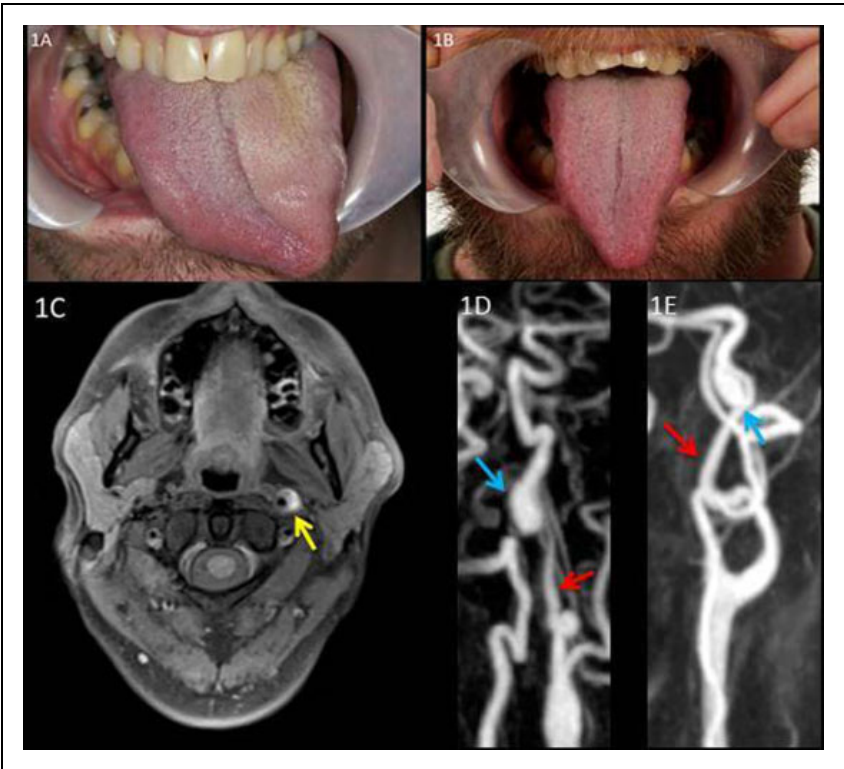

Figure I. Clinical photography demonstrating tongue deviation and resolution, and MRI demonstrating mural high signal and thickening and MR angiography demonstrating carotid stenosis and pseudoaneurysm.

A 40-year-old man presented with a 2-week history of headache followed by 5 days of mild dysarthria. He had no history of trauma and no preceding symptoms. The patient's tongue deviated to the left (Figure 1A) with no other neurological signs.

Magnetic resonance (MR) imaging of the brain was normal and contrast-enhanced MR angiogram demonstrated narrowing of the left internal carotid artery (ICA; red arrow Figure 1D) lumen associated with high signal intramurally and expansion suggesting dissection (yellow arrow) and pseudoaneurysm (yellow/blue arrows; Figure 1C and D). Treatment was with aspirin $300 \mathrm{mg}$ for 2 weeks followed by $75 \mathrm{mg}$ daily.

There was good resolution of symptoms and tongue deviation (Figure 1B) at 3 months. Repeat arterial imaging showed persisting ICA (red) pseudoaneurysm (blue; Figure 1E).

The incidence of spontaneous cervical artery dissection is around 2.5 to 5 per $100000,{ }^{1}$ causing up to $25 \%$ of stroke in younger populations. ${ }^{2}$ Cases sometimes cause isolated cranial nerve palsies, most frequently $\mathrm{CNXII}^{3}$
The hypoglossal nerve provides motor innervation to the tongue and arises from the ventral surface of the medulla; it then traverses the hypoglossal canal. On exiting the canal, the nerve runs beneath the ICA and the internal jugular vein.

The relationship between the nerve and ICA explains how mural expansion may cause nerve compression. Not all dissection results in vascular expansion, however. Sometimes it is the nutrient arteries which become occluded by vessel wall damage, or distal embolization. ${ }^{3}$ We suspect a nutrient artery lesion in our case due to clinical improvement without aneurysm resolution.

\section{Authors' Note}

Authors would like to acknowledge the contribution of the medical illustration department at the Pennine Acute Hospitals NHS Trust.

\section{Declaration of Conflicting Interests}

The authors declared no potential conflicts of interest with respect to the research, authorship, and/or publication of this article.

\section{Funding}

The authors received no financial support for the research, authorship, and/or publication of this article.

\section{References}

1. Schievink WI. Spontaneous dissection of the carotid and vertebral arteries. N Engl J Med. 2001;344(12):898-906. doi:10.1056/ NEJM200103223441206.

2. Debette S, Leys D. Cervical-artery dissections: predisposing factors, diagnosis, and outcome. Lancet Neurol. 2009;8(7): 668-678. doi:10.1016/S1474-4422(09)70084-5.

3. Mokri B, Silbert PL, Schievink WI, Piepgras DG. Cranial nerve palsy in spontaneous dissection of the extracranial internal carotid artery. Neurology. 1996;46(2):356-359. doi:10.1212/WNL.46.2.356.

\footnotetext{
'University of Manchester, Manchester, United Kingdom

${ }^{2}$ Pennine Acute Hospitals NHS Trust, Manchester, United Kingdom

${ }^{3}$ Salford Royal NHS Foundation Trust, Manchester, United Kingdom
}

\section{Corresponding Author:}

Martin Punter, Salford Royal NHS Foundation Trust, Manchester, United Kingdom.

Email: martin.punter@manchester.ac.uk 